УДК 631.527:633.14

DOI 10.18101/2587-7148-2020-2-14-20

\title{
ПОТЕНЦИАЛ ПРОДУКТИВНОСТИ СОРТОВ ЯРОВОГО ОВСА БУРЯТСКОЙ СЕЛЕКЦИИ В УСЛОВИЯХ АРИДИЗАЦИИ
}

\author{
А. С. Билтуев, А. К. Уланов \\ (C) Билтуев Александр Семенович \\ кандидат биологических наук, \\ Бурятский научно-исследовательский институт сельского хозяйства \\ Россия, 670045, г. Улан-Удэ, ул. Третьякова 25 «з» \\ E-mail: sbiltuev@mail.ru

\section{(C) Уланов Александр Кимович} \\ доктор сельскохозяйственных наук, \\ Бурятский научно-исследовательский институт сельского хозяйства \\ Россия, 670045, г. Улан-Удэ, ул. Третьякова 25 «з» \\ E-mail: sasha.ulanov.71@mail.ru
}

Представлены результаты сравнительного изучения урожайности районированных в различные годы сортов овса инорайонной селекции: Удыч-Жулты, Немчиновский-2, Сельма; сортов выведенных в Бурятском научно-исследовательском институте сельского хозяйства: Догой, Баргузин, Гэсэр, Мэрген и перспективного селекционного номера Тамир СП-502. Сортоиспытание проводилось в условиях сухостепной зоны Бурятии в богарных условиях без применения минеральных удобрений. Путем проведения дисперсионного и корреляционно-регрессионного анализов изучено влияние климатических факторов на продуктивность зерна овса. Выявлено, что наиболее значимое влияние на урожай зерна овса в условиях сухой степи Забайкалья оказали условия увлажнения в два критических периода: в первые тридцать дней от времени посева $(\mathrm{r}=0,96 \ldots 0,99)$ и количество осадков за август $(\mathrm{r}=0,80 \ldots 0,86)$. Наибольшее влияние на формирование урожая зерна оказывали количество осадков выпавших в первый критический период. Недостаток увлажнения приводил к изреживанию всходов и закладке укороченной метелки. Осадки, выпавшие в более поздние сроки, вызывают появление второй волны всходов овса, которые развиваются по типу подгона и не успевают сформировать полноценное зерно ко времени уборки. Условия увлажнения во второй критический период, во время формирования и налива зерна оказали значительно меньший эффект на урожай, чем осадки весны и начала лета. В среднем за период исследований продуктивность перспективного номера Тамир (СП-502) была наивысшей, превышение над стандартом Догой составило $18,2 \%$, над другими среднеспелыми сортами - 6,7-25,0\%.

Ключевые слова: яровой овес, урожайность зерна, сортоиспытание, регрессионная модель.

\section{Для цитирования}

Билтуев А. С., Уланов А. С. Потенциал продуктивности сортов ярового овса бурятской селекции в условиях аридизации // Вестник Бурятского государственного университета. Биология, география. 2020. № 2. С. 14-20. 
А. С. Билтуев, А. К. Уланов Потенциал продуктивности сортов ярового овса бурятской селекции в условиях аридизации

Яровой овес в Республике Бурятия является основной зернофуражной культурой и главным компонентом различного рода мешанок для производства сенажа, зерносенажа и силоса. Селекционерами Бурятского НИИСХ, в разные годы, были созданы сорта овса, районированные на территориях Восточной Сибири. Генетическим материалом для них послужили как местные, так и инорайонные сорта и линии. Различия климатических условий в период их селекции способствовали созданию сортов с различными адаптивными способностями к изменчивым условиям аридной зоны.

Согласно «Системы земледелия Республики Бурятия» (2018) площадь овса для создания оптимального хлебо-фуражно-семенного баланса в примерной структуре использования пашни должна составлять 42-46 тыс. га или 43-46\% в структуре посевов зерновых культур. Однако урожайность овса в степной и сухостепной зонах подвержена высокой вариабельности, основной причиной которой является значительная изменчивость погодных условий, высокая вероятность проявления засухи, особенно на начальных этапах развития. И если оценка агротехнологических приемов возделывания зерновых культур в целом, и в частности овса, возможного риска падения урожая в сухой год и потенциального роста продуктивности в благоприятный по увлажнению период по результатам многолетней выборки данных ( $\mathrm{n}=20-26)$ полевых стационаров Бурятского НИИСХ проведена (Уланов, Будажапов, 2019), то прогнозирование зерновой продуктивности сортов ярового овса местной селекции ранее не проводилось. Цель исследования - изучить влияние климатических условий на зерновую продуктивность районированных инорайонных и местных сортов ярового овса.

\section{Объекты, методы исследований}

Изучение связей зерновой продуктивности ярового овса с климатическими условиями периода вегетации проведено нами в 2009-2013 гг. на основе данных конкурсного испытания инорайонных сортов: Удыч-Жулты, Немчиновский-2, Сельма, а также сортов селекции Бурятского НИИСХ: Догой, Баргузин, Гэсэр, Мэрген и перспективного номера Тамир СП-502.

Средняя длина вегетационного периода у этих вариантов составляла: УдычЖулты - 75, Немчиновский-2-77, Сельма - 79, Догой - 78, Баргузин - 79, Гэсэр — 77, Мэрген - 78, Тамир СП-502-78 дней. В основном, все изучаемые сорта и селекционный номер относятся к группе среднеспелых сортов, относительно скороспелым является сорт Удыч-Жулты. Исследования проводились по общепринятой методике государственного сортоиспытания (Методика..., 1989).

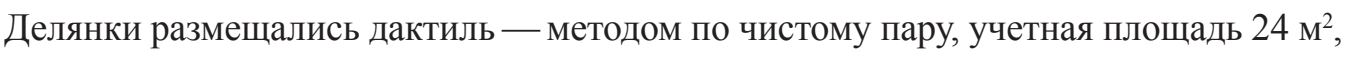
повторность трехкратная. Норма высева - 4,5 млн. всхожих семян на гектар. Посев проводился в конце второй декады мая. Уборка механизированная, комбайном Sampo-130, при наступлении хозяйственной спелости 80\% зерен. Урожай приве- 
ден к стандартной влажности и 100\% чистоте. Анализ адаптивного потенциала сортов и номеров проведен методами дисперсионного и регрессионого анализов по S. A. Eberchart, W.A. Russel (1966) и В. З. Пакудину, Л. М. Лопатиной (1984).

Сортоиспытание проводилось в центральной сухостепной зоне на опытном поле Бурятского НИИСХ на каштановых почвах, обладающих низким потенциальным плодородием: содержание гумуса - 1,35 $\pm 0,11 \%$, общего азота $-0,12 \pm 0,01 \%$, близкой к нейтральной реакцией среды $\left(\mathrm{pH}_{\text {вод. }} 6,5 \pm 0,1\right)$, высоким содержанием подвижного $\mathrm{P}_{2} \mathrm{O}_{5}(231 \pm 22$ мг/кг) и обменного К $2 \mathrm{O}(101 \pm 14$ мг/кг) по Чирикову.

Климатические условия вегетации овса характеризовались значительным дефицитом осадков при относительно благоприятном режиме теплообеспеченности в период вегетации овса (рис. 1). В период исследований наблюдалась значительная изменчивость поступления гидротермических ресурсов. Наименее благоприятные условия обычно сопутствовали началу вегетации овса, т. к. для сухой степи Бурятии характерно наступление засухи в весенний и раннелетний период, ГТК за майиюнь по Селянинову - 0,75. Более благоприятные условия наступают в середине вегетации. По этой причине регрессионные модели продуктивности построены для весеннего - раннелетнего периода с 20 мая по 20 июня.

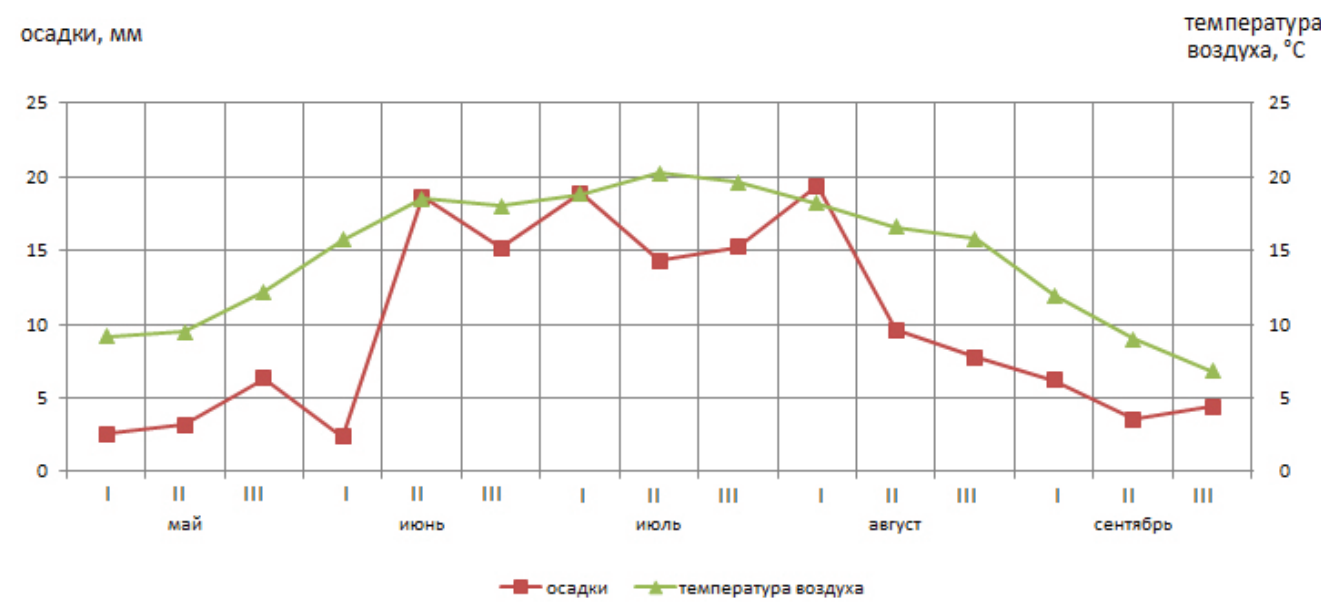

Рис. 1. Количества осадков и температур воздуха (среднее 2009-2013 гг.)

\section{Результаты и их обсуждение}

Основным фактором, лимитирующим продуктивность овса в зоне проведения наших исследований, является дефицит атмосферного увлажнения в различные периоды роста и развития растений. В целом, по совокупности факторов, относительно благоприятные условия для роста и развития овса сложились в 2009 и 2012 годы. В эти годы были получены наибольшие средние по сортам урожаи, соответственно 28 и 35 ц/га. В наиболее засушливый 2010 г. средняя 
A. С. Билтуев, А. К. Уланов Потенциал продуктивности сортов ярового овса бурятской селекции в условиях аридизации

урожайность зерна составила 3,5 ц/га. Изучаемые сортообразцы обладали различной продуктивностью в зависимости от происхождения (табл. 1).

Таблица 1

Урожайность зерна сортообразцов ярового овса (ц/га)

в конкурсном сортоиспытании (2009-2013 гг.)

\begin{tabular}{|l|l|c|c|c|}
\hline$№$ & Сортообразец & Ycp & $\lim$ & V,\% \\
\hline 1 & Догой - st & 19,1 & $3,9-31,7$ & 60,0 \\
\hline 2 & Удыч-Жулты & 18,68 & $4,0-33,0$ & 58,3 \\
\hline 3 & Немчиновский-2 & 18,98 & $3,8-33,0$ & 61,7 \\
\hline 4 & Сельма & 20,16 & $2,6-36,2$ & 63,9 \\
\hline 5 & Баргузин & 18,06 & $3,3-32,8$ & 60,8 \\
\hline 6 & Гэсэр & 20,02 & $4,2-36,2$ & 61,4 \\
\hline 7 & Мэрген & 21,16 & $3,9-36,8$ & 59,2 \\
\hline 8 & Тамир (СП-502) & 22,58 & $3,4-40,2$ & 64,0 \\
\hline & НСР $_{05}$ & 9,5 & & \\
\hline
\end{tabular}

Примечание: Үср - продуктивность зерна овса

В среднем за период исследований продуктивность сортообразца Тамир (СП-502) была наивысшей. Он превысил по этому показателю все образцы на 6,7-25,0\%, а стандарт Догой на 18,2\%. Между тем, в связи с высокой вариабельностью различия по урожайности сортов по годам сортоиспытаний не были достоверными.

Корреляционный анализ выявил высокую зависимость $(\mathrm{r}=0,96 \ldots 0,99)$ урожайности овса у всей совокупности среднеспелых сортов и перспективного номера от условий увлажнения в первые тридцать дней от времени посева, с третьей декады мая по вторую декаду июня ( $\mathrm{w}_{1}$, мм). Регрессионные модели зависимости урожайности $\mathrm{Y}(ц /$ га) от условий увлажнения позволили оценить адаптационный потенциал изученных образцов (табл. 2).

Наиболее отзывчивым на увлажнение оказался Тамир (СП-502), для которого каждые 10 мм осадков, выпадавшие в этот период, позволяли получать дополнительно 9 ц/га зерна. Урожайность сортов Баргузин и Удыч-Жулты в меньшей степени зависела от увлажнения периода всходы-кущение, на каждые 10 мм осадков они обеспечивали дополнительно 6,8 ц/га. Влияние температурного режима на урожай было менее существенным $(\mathrm{r}=-0,49 \ldots-0,54)$. В данные сроки растения проходили фазы всходы и кущения. Условия увлажнения этого периода определяли полевую всхожесть, число колосков в колосе и листьев главного стебля, мощность корневой системы.

Таблица 2

Регрессионные модели продуктивности зерна овса по условиям увлажнения за период 20 мая - 20 июня

\begin{tabular}{|l|l|l|l|}
\hline № & Вариант (сорт, номер) & Модель & $\mathrm{R}^{2}$ \\
\hline 1 & Догой - st & Ү(ц/га $)=0,73 \mathrm{w}_{1}($ мм $)-0,79$ & 0,99 \\
\hline 2 & Удыч-Жулты & Ү(ц/га) $=0,68 \mathrm{w}_{1}($ мм $)+0,14$ & 0,96 \\
\hline
\end{tabular}




\begin{tabular}{|l|l|l|l|}
\hline 3 & Немчиновский-2 & $\mathrm{Y}(ц /$ га $)=0,74 \mathrm{w}_{1}($ мм $)-1,27$ & 0,99 \\
\hline 4 & Сельма & $\mathrm{Y}(ц /$ га $)=0,81 \mathrm{w}_{1}($ мм $)-1,94$ & 0,97 \\
\hline 5 & Баргузин & $\mathrm{Y}\left(ц /\right.$ га) $=0,68 \mathrm{w}_{1}($ мм $)-0,60$ & 0,96 \\
\hline 6 & Гэсэр & $\mathrm{Y}(ц /$ га $)=0,77 \mathrm{w}_{1}($ мм $)-1,06$ & 0,97 \\
\hline 7 & Мэрген & $\mathrm{Y}(ц /$ га $)=0,79 \mathrm{w}_{1}($ мм $)-0,38$ & 0,98 \\
\hline 8 & Тамир $($ СП-502) & $\mathrm{Y}(ц / г а)=0,90 \mathrm{w}_{1}($ мм $)-2,20$ & 0,97 \\
\hline
\end{tabular}

Примечание: Y(ц/га) — урожайность зерна овса, w1(мм) — количество осадков с третьей декады мая по вторую декаду июня, $\mathrm{R}^{2}$ — коэффициент детерминации.

Второй по значимости критический период формирования урожая связан с фазами цветения, формирования зерновки и налива которые преимущественно проходили в августе. Выявлена сильная зависимость $(\mathrm{r}=0,80 \ldots 0,86)$ продуктивности зерна овса с количеством осадков за этот месяц ( $\left.\mathrm{w}_{2}, \mathrm{Mм}\right)$.

При благоприятном сочетании метеорологических условий в наиболее критические периоды развития овса отмечена наибольшая продуктивность растений (2009 и 2012 гг.), а при низком увлажнении в эти сроки она была минимальной (2010 г.). Эмпирические модели продуктивности сортов в зависимости от условий увлажнения в наиболее критические периоды имели вид многофакторных линейных моделей (табл. 3).

Таблица 3

Многофакторные регрессионные модели продуктивности зерна овса

\begin{tabular}{|c|c|c|c|}
\hline № & Вариант (сорт, номер) & Модель & $\mathrm{R}^{2}$ \\
\hline 1 & Догой - st & $\mathrm{Y}(ц /$ га $)=0,71 \mathrm{w}_{1}($ мм $)+0,02 \mathrm{w}_{2}($ мм $)-0,99$ & 0,99 \\
\hline 2 & Удыч-Жулты & $\mathrm{Y}(ц /$ га $)=0,71 \mathrm{w}_{1}($ мм $)+0,01 \mathrm{w}_{2}($ мм $)-1,15$ & 0,97 \\
\hline 3 & Немчиновский-2 & $\mathrm{Y}(ц /$ га $)=0,70 \mathrm{w}_{1}($ мм $)+0,04 \mathrm{w}_{2}$ (мм) $-1,81$ & 0,99 \\
\hline 4 & Сельма & $\mathrm{Y}(ц /$ га $)=0,80 \mathrm{w}_{1}($ мм $)+0,01 \mathrm{w}_{2}($ мм $)-0,19$ & 0,98 \\
\hline 5 & Баргузин & $\mathrm{Y}(ц /$ га $)=0,66 \mathrm{w}_{1}($ мм $)+0,01 w_{2}($ мм $)+0,68$ & 0,96 \\
\hline 6 & Гэсэр & $\mathrm{Y}(ц /$ га $)=0,76 \mathrm{w}_{1}($ мм $)+0,01 \mathrm{w}_{2}($ мм $)-0,87$ & 0,98 \\
\hline 7 & Мэрген & $\mathrm{Y}(ц /$ га $)=0,82 \mathrm{w}_{1}($ мм $)+0,01 \mathrm{w}_{2}($ мм $)-0,91$ & 0,99 \\
\hline 8 & Тамир (СП-502) & $\mathrm{Y}(ц /$ га $)=0,89 \mathrm{w}_{1}($ мм $)+0,02 \mathrm{w}_{2}($ мм $)-2,42$ & 0,97 \\
\hline
\end{tabular}

Примечание: $\mathrm{Y}(ц / г \mathrm{a})-$ урожайность зерна овса, $\mathrm{w}_{1}(\mathrm{мм})$ - количество осадков с третьей декады мая по вторую декаду июня, $\mathrm{w}_{2},($ мм) - количество осадков в августе.

В условиях сухой степи Забайкалья наибольшее влияние на формирование урожая зерна оказывает количество осадков выпавших за 30 дней от срока посева (Осипов, 1982). Недостаток увлажнения в этот период ведет к изреживанию всходов и закладке укороченной метелки. Осадки, выпавшие в более поздние сроки, вызывают появление второй волны всходов овса, которые развиваются по типу подгона и не успевают сформировать полноценное зерно ко времени уборки. Условия увлажнения в период формирования и налива зерна оказали значительно меньший эффект на урожай, чем осадки весны и начала лета, коэффициенты линейной регрессии при $\mathrm{w}_{2}$ (мм) были ниже аналогичных при $\mathrm{w}_{1}$ (мм) более чем в 18 раз. 
А. С. Билтуев, А. К. Уланов Потенциал продуктивности сортов ярового овса бурятской селекции в условиях аридизации

\section{Заключение}

При испытании сортов, районированных в разные годы в степи и сухой степи Забайкалья, выявлено, что наибольшую продуктивность зерна в условиях 20092013 гг. показал перспективный номер Тамир (СП-502), превышение над стандартом составило $18,2 \%$. Наименьшая урожайность зерна отмечена у сорта Баргузин. Номер Тамир (СП-502) обладал наибольшей способностью продуктивного использования осадков сухой степи Забайкалья в течение вегетации. Перспективный номер Тамир по результатам конкурсного сортоиспытания предлагается к передаче в Госкомиссию по сортоиспытаниям для районирования в 11 зоне.

\section{Литература}

1. Методика государственного сортоиспытания сельскохозяйственных культур. М., 1989. Вып. $2.194 \mathrm{c}$.

2. Пакудин В. З., Лопатина Л. М. Оценка экологической пластичности и стабильности сортов сельскохозяйственных культур // Сельскохозяйственная биология. 1984. № 4. С. 109-113.

3. Система земледелия Республики Бурятия: научно-практические рекомендации / под науч. ред. проф. А. П. Батудаева. Улан-Удэ: Изд-во БГСХА им. В. Р. Филиппова, 2018. 349 с.

4. Уланов А. К., Будажапов Л. В. Продуктивность каштановой почвы в зависимости от условий увлажнения при многолетнем воздействии севооборотов, приемов основной обработки почвы и удобрений // Земледелие. 2019. № 1. С. 15-18.

5. Eberchart S. A., Russel W. A. Stability parameters for comparing varieties // Crop Sci. 1966. Vol. 6.№ 1.P. $36-40$.

6. Осипов В. И. Зерновые культуры в Бурятии / В. И. Осипов.- Улан-Удэ: Бур. кн. издво, 1982.- $88 \mathrm{c}$.

THE POTENTIAL PRODUCTIVITY OF THE VARIETIES

OF SPRING OATS BURATSKI BREEDING IN CONDITIONS OF ARIDIZATION

A. S. Biltuev, A. K. Ulanov

Biltuev Alexander $S$.

Cand. Sci. (Bio),

Buryat research Institute of agriculture, 25 “z” Tretyakov str., Ulan-Ude, 670045, Russia

E-mail: sbiltuev@mail.ru

Ulanov Alexander $K$.

Dr. Sci. (Agricult.),

Buryat research Institute of agriculture, 25 “z” Tretyakov str., Ulan-Ude, 670045, Russia

E-mail: sasha.ulanov.71@mail.ru

The results of a comparative study of the yield of oat varieties zoned in different years of innorayona selection: Udych-Zhulty, Nemchinovsky-2, Selma; varieties bred in the Buryat research Institute of agriculture: Dogoy, Barguzin, Geser, Mergen and the prospective selection number Tamir SP-502. Variety testing was carried out in the conditions of the dry-steppe zone of Buryatia in bogarny conditions without the use of mineral fertilizers. The influence of climate factors on oat grain productivity was studied by conducting dispersion and correlation-regression analyses. It was found that the most significant impact on the oat grain yield in the conditions 
of the dry steppe of Transbaikalia was caused by moisture conditions in two critical periods: in the first thirty days from the time of sowing $(r=0.96 \ldots 0.99)$ and the amount of precipitation in August $(r=0.80 \ldots 0.86)$. The greatest influence on the formation of the grain harvest was the amount of precipitation that fell during the first critical period. Lack of moisture led to thinning of seedlings and laying a shortened panicle. Precipitation that falls at a later time causes the appearance of a second wave of oat seedlings, which develop according to the type of fit and do not have time to form a full-fledged grain by the time of harvesting. Moisture conditions in the second critical period, during the formation and filling of grain had a much smaller effect on the crop than the precipitation of spring and early summer. On average, during the research period, the productivity of the prospective Tamir number (SP-502) was the highest, exceeding the Doga standard by $18.2 \%$, and over other middle - aged varieties by $6.7-25.0 \%$.

Keywords: spring oats, grain yield, variety testing regression model. 